\title{
PID Studies on Position Tracking Control of an Electro-Hydraulic Actuator
}

\author{
Norle la Ishak ${ }^{1, *}$, Mazidah Tajjudin ${ }^{1}$, Hashimah Is mail ${ }^{2}$, Mohd Hezri Fazalul Rahiman ${ }^{1}$, Yahaya Md Sam ${ }^{3}$, \\ Ramli Adnan ${ }^{1}$
}

${ }^{1}$ Faculty of Electrical Engineering, UiTM , 40450, Shah Alam, Selangor, Malay sia
${ }^{2}$ Faculty of Engineering, UNISEL, 45600 Bestari Jaya, Selangor, Malaysia
${ }^{3}$ Faculty of Electrical Engineering, UTM Sekudai, 81310 Johor, Malay sia

\begin{abstract}
Despite the application of advanced control technique to imp rove the performance of electro-hydraulic position control, Proportional Integral Derivative (PID) control scheme seems able to produce satisfactory result. PID is preferable in industrial applications because it is simple and robust. The main problem in its application is to tune the parameters to its optimum values. This study will look into an optimization of PID parameters using Nelder-Mead (N-M) compare with self-tuning fuzzy approach for electro-hydraulic position control system. The electro-hydraulic system was represented by an Auto-regressive with Exogenous Input (ARX) model structure obtained through MATLAB System Identification Toolbox. Second-order and third-order model of the system had been evaluated. Simu lation and real-time studies show that the output produced the best response in terms of transient speed and Root Mean Square Error (RMSE) performance criteria.
\end{abstract}

Keywords Electro-Hydraulic System, PID Control, Nelder-Mead Optimization, Self Tuning Control, System Identification

\section{Introduction}

Electro-hydraulic actuators are very important elements for industrial processes because they provide linear movement, fast response and accurate positioning of heavy load. Recently, hydraulic actuator system has gained popularity in many applications such as in paper mills, aircrafts, and automotive industries where linear movement, fast response, and accurate positioning with heavy loads are required.

However, the nonlinear nature of such actuators represents a hard challenge in designing a perfect controller for this actuator. Difficulties in identifying an accurate model of inherently nonlinear and time-varying dynamics make controller design more complicated. Many researchers have used advanced control strategies to improve the system performance mainly in tracking control and motion control ability. Chen et al.[1] and Ghazali et al.[2] had applied sliding mode control, many others had applied hybrid of fuzzy and PID and adaptive PID control using fuzzy[3-6]. Their studies show that the PID control laws are sufficient to control the hydraulic actuator as desired.

Feedback control system design using PID controller has

\footnotetext{
* Corresponding author:

norlelaishak@salam.uitm.edu.my(Norlela Ishak)

Published online at http//journal.sapub.org/control

Copyright (C) 2012 Scientific \& Academic Publishing. All Rights Reserved
}

been adopted in this study because it is simple and robust when applied within specified operating range. The equation for a typical dig ital PID controller is given in Eq. (1).

$$
\mathrm{u}(\mathrm{k})=\mathrm{k}_{\mathrm{p}} \mathrm{e}(\mathrm{k})+\mathrm{k}_{\mathrm{i}} \sum_{\mathrm{j}=0}^{\mathrm{k}} \mathrm{e}(\mathrm{j})+\mathrm{k}_{\mathrm{d}}[\mathrm{e}(\mathrm{k})-\mathrm{e}(\mathrm{k}-1)]
$$

Where $\mathrm{e}(\mathrm{k})$ is the error signal.

To ensure a good performance of the controller, suitable values for each parameter namely $K_{p}, K_{i}$ and $K_{d}$ must be tuned optimally. Classical PID tuning approach such as Ziegler-Nichols and Cohen-Coon requires information of ultimate gain and ultimate period of oscillation in order to calculate the controller parameters. The disadvantage of experimentally determining the critical parameters is that the system can lead to a state of instability. Finding a stability boundary in systems with large time constants can be very time-consuming[4].

In an effort to imp rove the performance of PID tuning for processes with changing dynamic properties, this study will applied auto matic tuning based on Nelder-Mead optimizatio $\mathrm{n}$ and self-tuning fuzzy to tune the PID parameters. The optimization a lgorith $m$ will search for optimal values of $K_{p}$, $K_{i}$ and $K_{d}$ from a given specified step response requirements and actuator constraints. The detail will be explained in section optimization PID. The tuning will be done by simulation. The performance controller will be evaluated using a sinusoidal signal with time-varying frequency and demonstrated on a hydraulic position control test bed. 


\section{System Identification}

This study was implemented on an electro-hydraulic system with single-ended cylinder type of actuator and the pressurized fluid flow is control by a proportional valve. The bidirectional cy linder has 150 millimeter stroke length; 40 millimeter bore size and 25 millimeter rod size. The wire displacement sensor is mounted at the top of cylinder rod.

The complete experimental setup for data collection and real-time studies is shown in Figure 1. The data collection for input-output test of the plants was done using MATLAB Real-time workshop via Advantech PCI-1716 interface card. The input signal used for model identification was a multi-frequency sine waves generated using three different frequencies as represented by Eq. (2).

$$
V_{\text {in }}(k)=2 \cos 0.3 t_{s} k+2 \cos 4 t_{s} k+\cos 6 t_{s} k
$$

where $t_{s}$ is the sampling time

A set of data that cons is ts of the input voltage and actuator displacement as shown in Figure $2 \mathrm{a}$ and $2 \mathrm{~b}$ was observed for 5000 time steps experiment with $40 \mathrm{~ms}$ of sampling time under the off-line model identification.

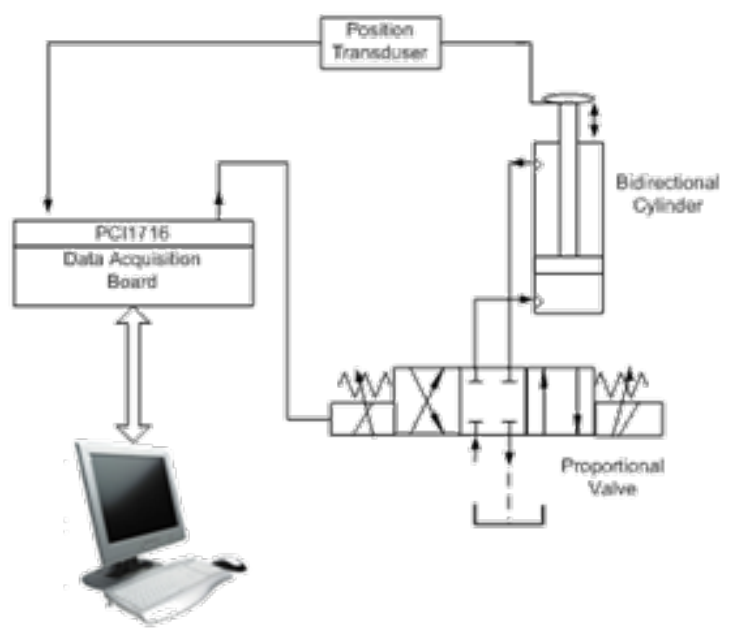

Figure 1. Experimental setup of electro-hydraulic system

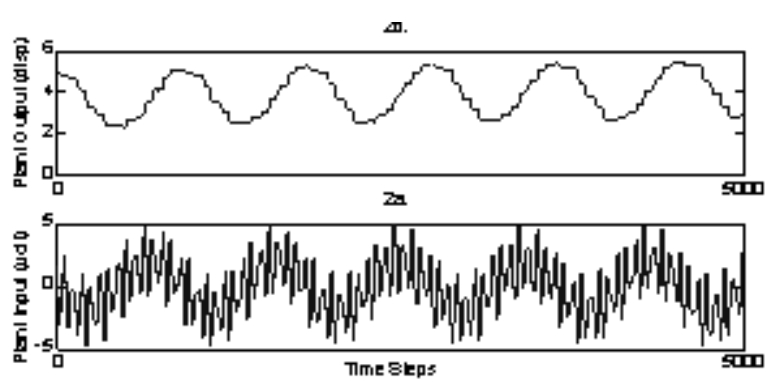

Figure 2. Input and Output signal for model identification

When the system was perturbed by a signal up to third harmonics, the model that can be obtained is limited to second and third order only. Higher orders model may produce unstable output[7].

For linear identification process, discrete time ARX model structure was selected for this study primarily to represent the system for PID controller. The ARX model is a simple model and can be presented in a simple linear difference equation. In this study, second-order and third-order ARX model had been estimated with best fit of more than $80 \%$. Four possible models were obtained as tabulated in Table 1. All models are stable and of minimum phase as can be evaluated from the location of its poles and zeros. The pole-zero maps are given in Figure 3.

Table 1. ARX model representation with best fit criteria

\begin{tabular}{|c|c|c|}
\hline $\begin{array}{c}\text { Model } \\
\text { Order }\end{array}$ & Polynomial & Best fit \\
\hline ARX211 & $\begin{array}{c}\mathrm{A}(\mathrm{q})=1-1.795 \mathrm{q}^{-1}+0.7954 \mathrm{q}^{-2} \\
\mathrm{~B}(\mathrm{q})=0.002569 \mathrm{q}^{-1}\end{array}$ & $82.03 \%$ \\
\hline ARX221 & $\begin{array}{c}\mathrm{A}(\mathrm{q})=1-1.879 \mathrm{q}^{-1}+0.8796 \mathrm{q}^{-2} \\
\mathrm{~B}(\mathrm{q})=0.01088 \mathrm{q}^{-1}-0.009358 \mathrm{q}^{-2}\end{array}$ & $84.24 \%$ \\
\hline ARX311 & $\mathrm{A}(\mathrm{q})=1-2.173 \mathrm{q}^{-1}+1.553 \mathrm{q}^{-2}-0.38 \mathrm{q}^{-3}$ & $86.53 \%$ \\
\hline ARX331 & $\begin{array}{c}\mathrm{A}(\mathrm{q})=1-2.099 \mathrm{q}^{-1}+1.35 \mathrm{q}^{-2}-0.2505 \mathrm{q}^{-3} \\
\mathrm{~B}(\mathrm{q})=0.006213 \mathrm{q}^{-1}-0.002792 \mathrm{q}^{-2}-0.001707 \mathrm{q}^{-3}\end{array}$ & $87.57 \%$ \\
\hline
\end{tabular}

Based on best fit performance criteria as expected, ARX331 is the best model to represent the system. Generally, model representation with adequate accuracy is required in order to design a controller that will drive the output in a desired manner[8]. This study will determine how accurate the model would be considered as adequate model for PID control imp lementation.

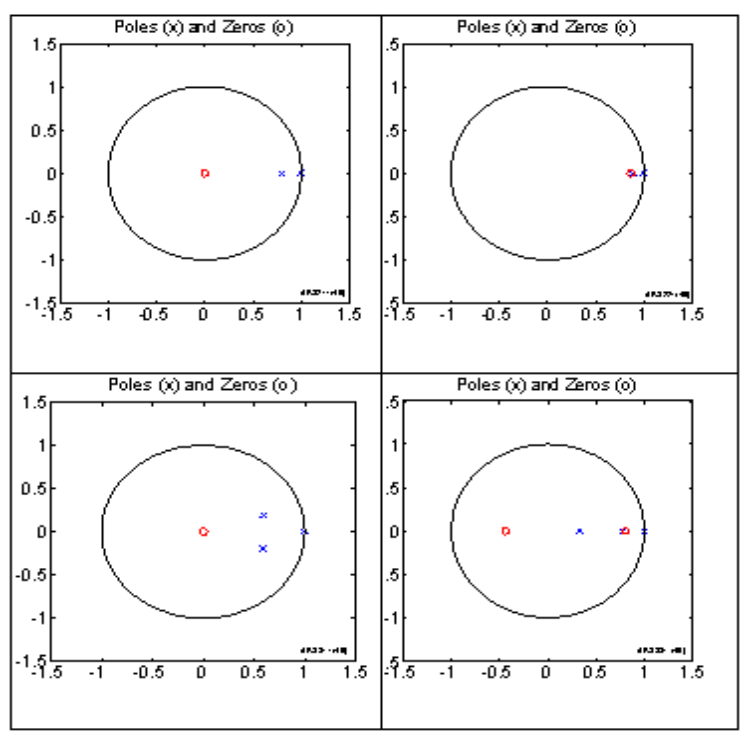

Figure 3. Pole-Zero Map

\section{PID Optimization}

In this study, the PID parameters will be optimized using Nelder-Mead optimization and self-tuning Fuzzy approach. The Nelder-Mead technique was proposed by Nelder and Mead in 1965[9]. It is a simplex-based method to find a local minimum of a function of several variables. It attempts to minimize a nonlinear function of $\mathrm{n}$ variables without any derivative information. Th is method applied a pattern search approach with $\mathrm{k}+1$ dimensional shape where $\mathrm{k}$ is the number 
of variables to be optimized. A long the search, the initial simplex (polygon) will go through a process of reflection, expansion, contraction and shrinking until the function is minimized (or maximized). The procedure of Nelder-Mead search is listed in Table 2.

Table 2. N-M algorithm for 3 parameters

\begin{tabular}{|c|c|}
\hline $\begin{array}{r}\text { IF } \mathrm{f}(\mathrm{R})<\mathrm{f}(\mathrm{G}), \text { THEN perfo } \\
\text { ELSE perform Case }\end{array}$ & $\begin{array}{l}\text { e(i) }\{\text { either reflect or extend\} } \\
\text { her contract or shrink\} }\end{array}$ \\
\hline $\begin{array}{c}\text { BEGIN }\{\text { Case }(\mathrm{i})\} \\
\text { IF f(B) }<\mathrm{f}(\mathrm{R}) \mathrm{THEN} \\
\text { Replace W with } \mathrm{R} \\
\text { ELSE } \\
\text { Compute } \mathrm{E} \text { and } \mathrm{f}(\mathrm{E}) \\
\text { IF } \mathrm{f}(\mathrm{E})<\mathrm{f}(\mathrm{B}) \text { THEN } \\
\text { Replace W with E } \\
\text { ELSE } \\
\text { Replace W with R } \\
\text { ENDIF } \\
\text { ENDIF } \\
\text { END }\{\text { Case }(\mathrm{i})\}\end{array}$ & $\begin{array}{c}\text { IF } \mathrm{f}(\mathrm{C})<\mathrm{f}(\mathrm{W}) \text { THEN } \\
\text { Replace W with C } \\
\text { ELSE } \\
\text { Compute } \mathrm{S} \text { and } \mathrm{f}(\mathrm{S}) \\
\text { Replace W with S } \\
\text { Replace } \mathrm{G} \text { with } \mathrm{M} \\
\text { ENDIF } \\
\text { END }\{\text { Case(ii) }\}\end{array}$ \\
\hline
\end{tabular}

Nelder-Mead optimization still attracts researcher from many a reas even though it seems too colloquial[10-12]. It is a close relative to Particle Swarm Optimization (PSO) and Differential Evolution (DE)[13]. Wang et al.[14] applied this method for parameter estimating of chaotic system and Panigrahi and Pandi[15] applied Nelder-Mead along with Bacterial Foraging Optimization (BFO) to explore the search space to find the local minima for load dispatch .These shown that it is still the method of choice for many practitioners in optimization.

In this study, Nelder-Mead is applied to find the optimum value for $\mathrm{K}_{\mathrm{p}}, \mathrm{K}_{\mathrm{i}}$ and $\mathrm{K}_{\mathrm{d}}$ with the following constraints:

Rise time: $5 \mathrm{sec}$

Settling time: $10 \mathrm{sec}$

\%Overshoot: $10 \%$

Actuator cons traint: $\pm 5 \mathrm{~V}$

The controller will be optimized based on step response specifications within the limited range of controller output which is $\pm 5 \mathrm{~V}$. The system is required to operate at fast transient with minimum overshoot. The specifications given are the best that the optimization could perform.

The PID controller was optimized for all the identified models. Based on simu lation, the closed-loop output with the optimized PID controller is shown in Figure 4. From the figure, there are significant speed variations during transient response where ARX221 gives the highest speed followed by ARX311. But ARX311 response had slight overshoot which in some cases may not be tolerable because it will lead to increased steady-state error when apply into the proposed controller. In this study, the best response in terms of speed and overshoot was obtained from ARX221 and ARX331 model. The optimized PID shows satisfactory results where all the outputs lie within the boundaries. The PID parameters for each model are tabulated in Table 3. Based on the selected model, parameters of $\mathrm{K}_{\mathrm{p}}, \mathrm{K}_{\mathrm{i}}$ and $\mathrm{K}_{\mathrm{d}}$ will be tested in simulation and real-time into proposed controller.

Table 3. Optimized Pid Controller Parameters (N-M)

\begin{tabular}{|c|c|c|c|c|}
\hline & ARX211 & ARX221 & ARX311 & ARX331 \\
\hline$K_{b}$ & 2.9030 & 5 & 4.3130 & 4 \\
\hline$K_{i}$ & 0.1303 & 0.5 & 0.0988 & 0.2383 \\
\hline$K_{d}$ & 0.1954 & 0 & 0.0021 & 0.0380 \\
\hline
\end{tabular}
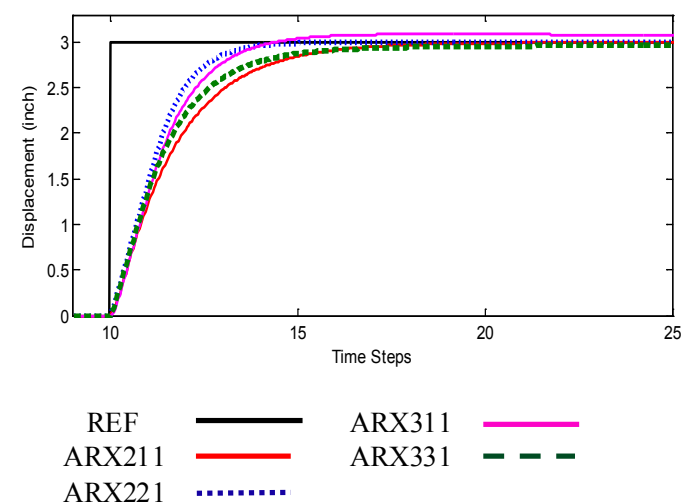

Figure 4. Closed-loop response with opt imized PID controller

This study also presents a development and implementation of the proposed self-tuning fuzzy PID controller in controlling the position variation of electro-hydraulic actuator. The self-tuning fuzzy PID controller is the combination of a classical PID and fuzzy controller. Self-tuning fuzzy PID controller means that the three parameters $K_{p}, K_{i}$ and $K_{d}$ of PID controller are tuned by using fuzzy tuner[16-17]. The coefficients of the conventional PID controller are not properly tuned for the nonlinear plant with unpredictable parameters variations. Hence, based on Nelder-Mead optimization parameters, it is necessary to automatically tune the PID parameters.

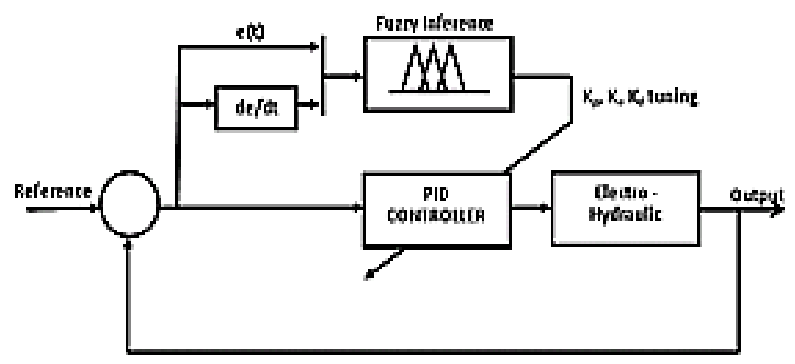

Figure 5. Structure of self-tuning fuzzy PID controller

In this study, the proposed structure of the self-tuning fuzzy PID controller is shown in Figure 5. There are two inputs to the fuzzy logic inference engine, the feedback error $e(t)$ and the derivative of error $d e(t) / d t$. The PID parameters are tuned by using fuzzy inference, which provide a nonlinear mapping fro $m$ the error and derivative of error to PID parameters.

The rules designed are based on the characteristics of the electro-hydraulic actuator and properties of the PID controller. Therefore, the fuzzy reasoning of fuzzy sets of outputs is gained by aggregation operation of fuzzy sets 
inputs and the designed fuzzy rules. The aggregation and defuzzyfication method are used respectively max-min and centroid method. Regarding to fuzzy structure, there are two inputs to fuzzy inference: error $e(t)$ and derivative of error $d e(t)$, and three outputs for each PID controller parameters respectively $\mathrm{K}_{\mathrm{p}}^{\prime}, \mathrm{K}_{\mathrm{i}}^{\prime}$ and $\mathrm{K}_{\mathrm{d}}^{\prime}$. Mamdani model is applied as structure of fuzzy inference with some modification to obtain the best value for $\mathrm{K}_{\mathrm{p}}, \mathrm{K}_{\mathrm{i}}$ and $\mathrm{K}_{\mathrm{d}}$. This is illustrate by Figure 6.

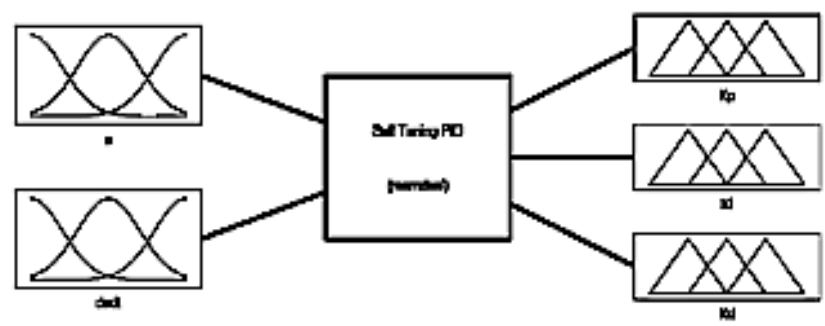

Figure 6. Fuzzy inference block

The range of each parameter was determined based on the Nelder-Mead optimization PID controller testing that had been conducted earlier. This part is important so that a feasible rule base with high frequency effic iency is obtained. The ranges of each parameters are :

$$
K_{p} \in[1,10] ; K_{i} \in[0,1] ; K_{d} \in[0,0.5] \text {. }
$$

Therefore, they can be calibrated over the interval $[0,1]$ as follows:

$$
\begin{array}{r}
\mathrm{K}_{\mathrm{p}}^{\prime}=\frac{\mathrm{K}_{\mathrm{p}}-\mathrm{K}_{\mathrm{p} \min }}{\mathrm{K}_{\mathrm{p} \max }-\mathrm{K}_{\mathrm{p} \min }}=\frac{\mathrm{K}_{\mathrm{p}}-1}{10-1} \\
\mathrm{~K}_{\mathrm{i}}^{\prime}=\frac{\mathrm{K}_{\mathrm{i}}-\mathrm{K}_{\mathrm{i} \min }}{\mathrm{K}_{\mathrm{i} \max }-\mathrm{K}_{\mathrm{i} \min }}=\frac{\mathrm{K}_{\mathrm{i}}-0}{1-0} \\
\mathrm{~K}_{\mathrm{d}}^{\prime}=\frac{\mathrm{K}_{\mathrm{d}}-\mathrm{K}_{\mathrm{d} \min }}{\mathrm{K}_{\mathrm{d} \max }-\mathrm{K}_{\mathrm{d} \min }}=\frac{\mathrm{K}_{\mathrm{d}}-0}{0.5-0}
\end{array}
$$

Hence, we obtain : $\mathrm{K}_{\mathrm{p}}=9 \mathrm{~K}_{\mathrm{p}}^{\prime}+1 ; \mathrm{K}_{\mathrm{i}}=\mathrm{K}_{\mathrm{i}}^{\prime} ; \mathrm{K}_{\mathrm{d}}=0.5 \mathrm{~K}_{\mathrm{d}}^{\prime}$

The membership functions of the inputs and outputs are shown in Figure 7a and 7b. Generally, the fuzzy rules are dependent on the control purpose and type of input-output signal parameter. Based on the membership function in Figure $7 \mathrm{a}$ and $7 \mathrm{~b}$, the fuzzy rules system was performed as given in Table 4. The linguistic variables used were Small(S), Medium Small(MS), Medium (M), Medium Big (MB), and Big (B). Since there were five linguistic variables that had been set, thus, 25 fuzzy rules were applied in the system. Centroid method defuzzification was used to get the definite values that were sent to PID controller. The whole systems were developed using Matlab Simu link environ ment.

Table 4. Rules of the fuzzy inference

\begin{tabular}{|c|c|c|c|c|c|}
\hline \multirow{2}{*}{ de/dt } & \multicolumn{5}{|c|}{ Error (e) } \\
\cline { 2 - 6 } & NB & NS & ZE & PS & PB \\
\hline NB & S & S & MS & MS & M \\
\hline NS & S & MS & MS & M & MB \\
\hline ZE & MS & MS & M & MB & MB \\
\hline PS & MS & M & MB & MB & B \\
\hline PB & M & MB & MB & B & B \\
\hline
\end{tabular}

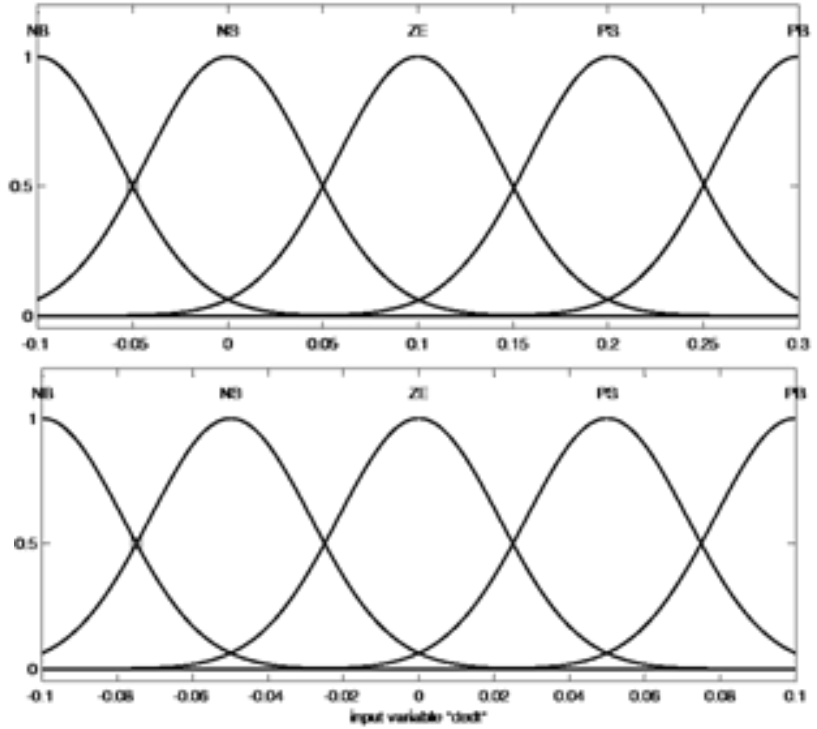

Figure 7a. Membership function of $\mathrm{e}(\mathrm{t})$ and de(t)

These levels are chosen from the characteristics and specification of the electro-hydraulic actuator. Figure 7a, shows the ranges of these inputs are -0.1 to 0.1 and -.01 to 0.3 , which are obtained from the absolute value of the system error and its derivative through the gains.

Figure $7 \mathrm{~b}$, shows the ranges of outputs $\mathrm{K}_{\mathrm{p}}^{\prime}, \mathrm{K}_{\mathrm{i}}$ and $\mathrm{K}_{\mathrm{d}}$ where the ranges from 1 to 10,0 to 1 and 0 to 0.5 .
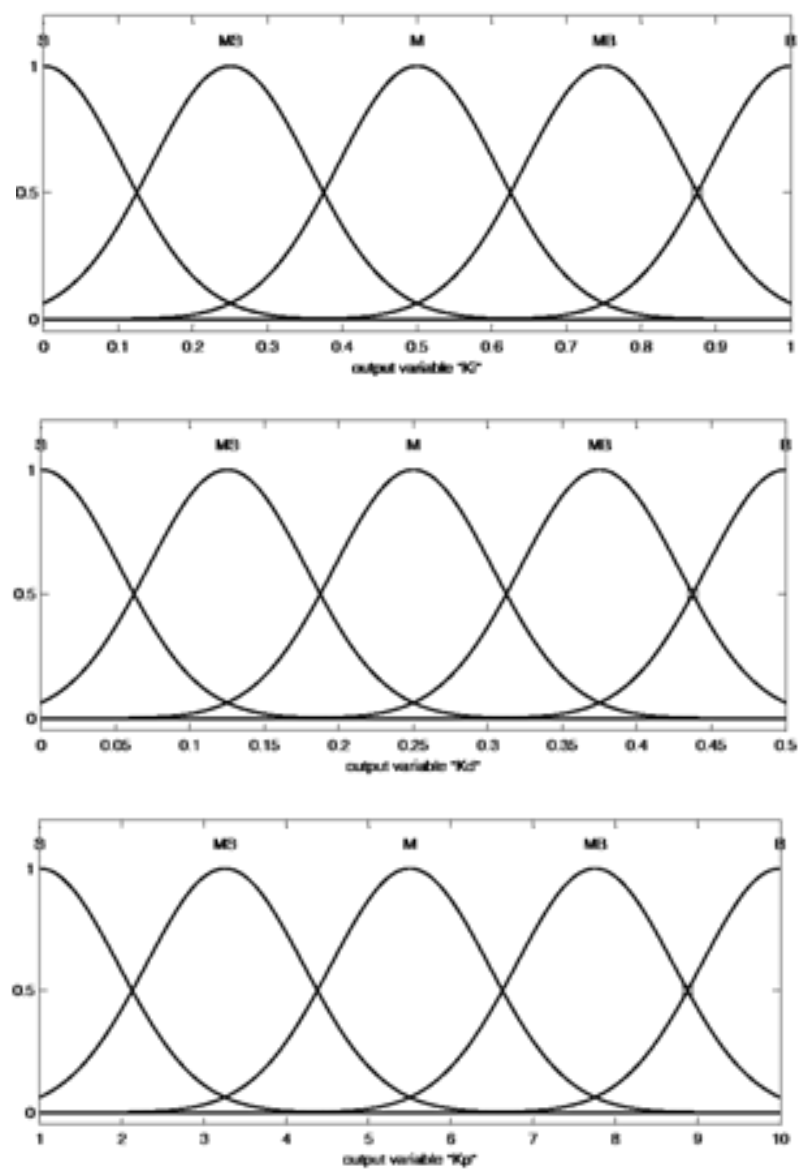

Figure 7b. Membership function of $\mathrm{K}_{\mathrm{p}}, \mathrm{K}_{\mathrm{i}}{ }_{\mathrm{i}}$ and $\mathrm{K}_{\mathrm{d}}$ 


\section{4 .Simulation and Real-Time Implementation}

The N-M optimized PID setting was used to simulate the system performance when subjected to step response and reference sinusoidal signal with time-varying frequency. Root mean square error (RMSE) was selected as the performance criteria. Table 5 summarizes the performance of the identified models. Based on RMSE index, ARX221 and ARX331 model has outperformed other models.

Table 5. RMSE performance crit eria for simulat ion Nelder-Mead

\begin{tabular}{|c|c|c|c|c|}
\hline RMSE (inch) & ARX21 1 & ARX221 & ARX31 1 & ARX331 \\
\hline Unit step & 0.2935 & $\mathbf{0 . 2 5 6 8}$ & 0.2880 & $\mathbf{0 . 2 7 6 1}$ \\
\hline Ref Sine & 0.1634 & $\mathbf{0 . 1 1 6 2}$ & 0.1501 & $\mathbf{0 . 1 3 5 6}$ \\
\hline
\end{tabular}

The ARX221 and ARX331 model then evaluated towards reference sinusoidal signal with time-varying frequency. The shape is chosen such that to demonstrated the ability of the controller to track the reference signal with changing frequency components. Figure 8 shows the output response for the sinusoidal signal with time-varying frequency for Nelder-Mead optimization.

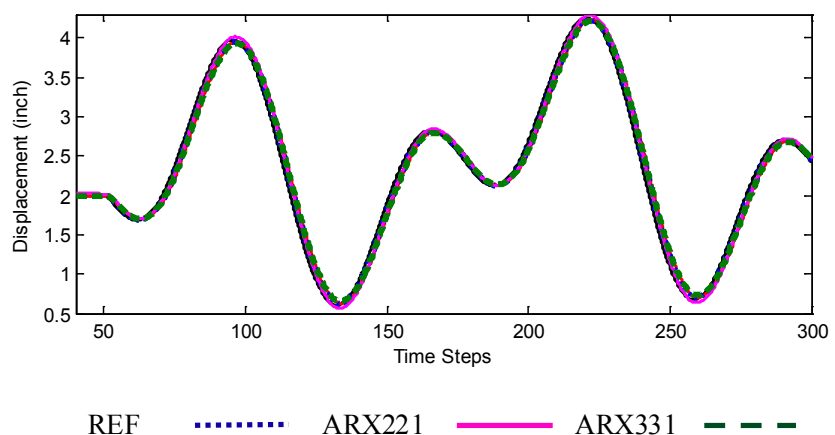

Figure 8. Simulation result of the sinusoidal responses of N-M PID

Based on the Nelder-Mead optimization, we proposed self-tuning fuzzy PID controller in controlling position variation of electro-hydraulic actuator. The parameters of each controller have been optimized based on Nelder-Mead algorith $\mathrm{m}$. In order to perform the output of the system, two types of input signal are applied respectively step input and sinusoidal input with time-varying frequency. For comparis on purposes, the root mean square error (RMSE) was selected as the performance criteria. Table 6 shows the overall results during simulation. The outputs of simulation for Nelder-Mead optimization and self-tuning fuzzy control are presented in Figure 9, 10, 11 and 12 below.

Table 6. RMSE performance criteria for simulation Nelder-Mead

\begin{tabular}{|c|c|c|c|c|}
\hline \multirow{2}{*}{$\begin{array}{c}\text { RMSE } \\
\text { (inch) }\end{array}$} & \multicolumn{2}{|c|}{ ARX221 } & \multicolumn{2}{c|}{ ARX331 } \\
\cline { 2 - 5 } & N-MPID & $\begin{array}{c}\text { FUZZY } \\
\text { PID }\end{array}$ & N-MPID & $\begin{array}{c}\text { FUZZY } \\
\text { PID }\end{array}$ \\
\hline Unit step & 0.2568 & 0.2532 & 0.2761 & 0.2623 \\
\hline Ref Sine & 0.1162 & 0.0813 & 0.1356 & 0.0843 \\
\hline
\end{tabular}

Based on the error analyses, control effort and observation on the tracking performance, the self-tuning fuzzy control provides more convenient and better performance in position tracking control. Compare with the Nelder-Mead PID control strategy, the self-tuning fuzzy PID controller reduced the error. This can observed from the RMSE index given in Table 6.

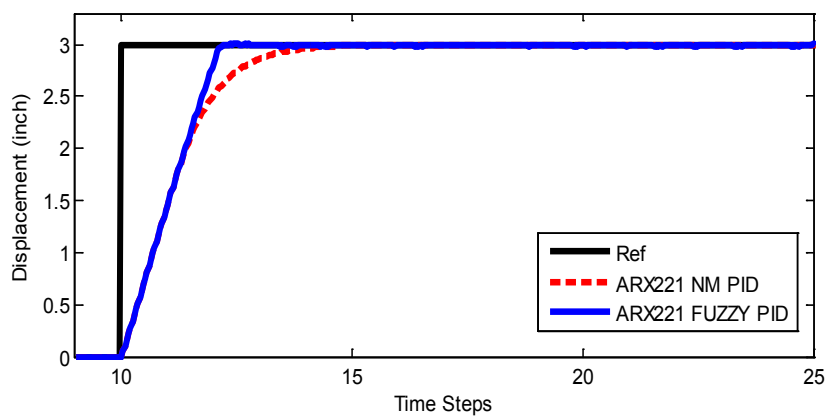

Figure 9. Simulation result of the step responses of N-M and Fuzzy PID (ARX221)

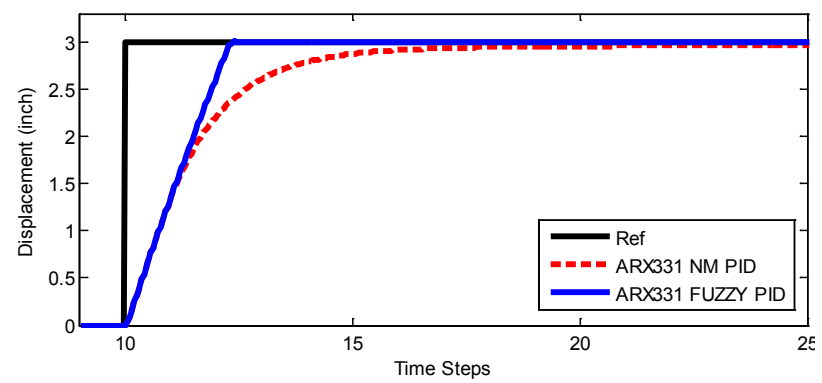

Figure 10. Simulation result of the step responses of N-M and Fuzzy PID (ARX331)

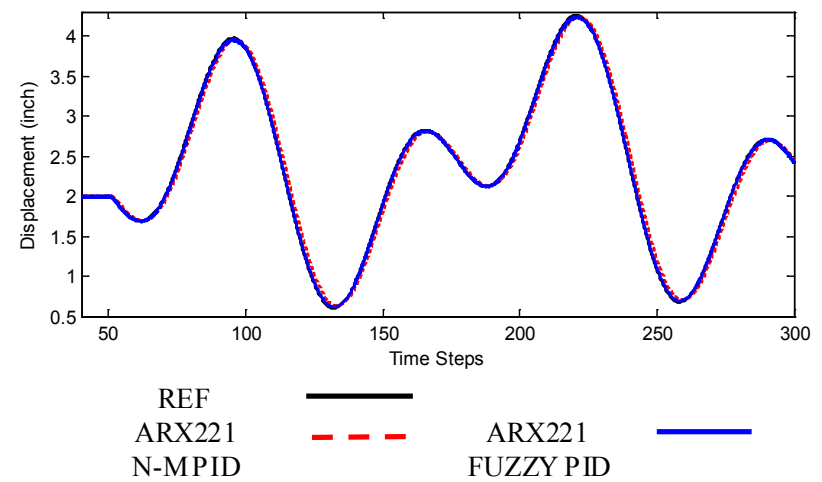

Figure 11. Simulation result of the sinusoidal responses of N-M and Fuzzy PID (ARX221)

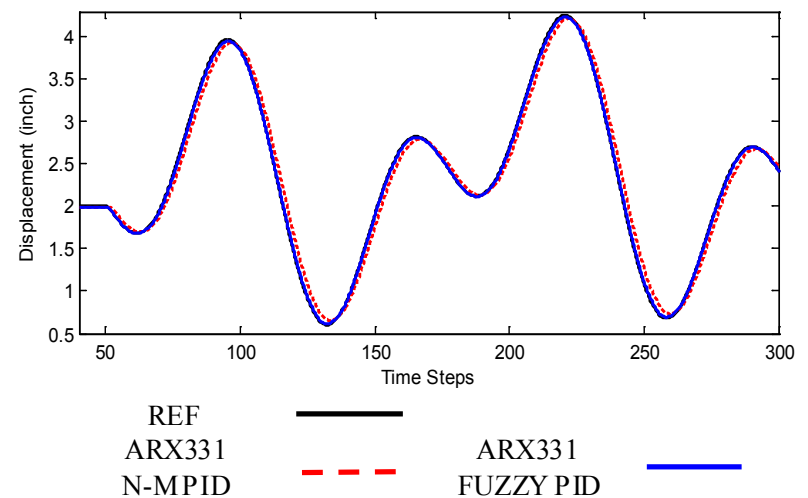

Figure 12. Simulation result of the sinusoidal responses of N-M and Fuzzy PID (ARX331) 


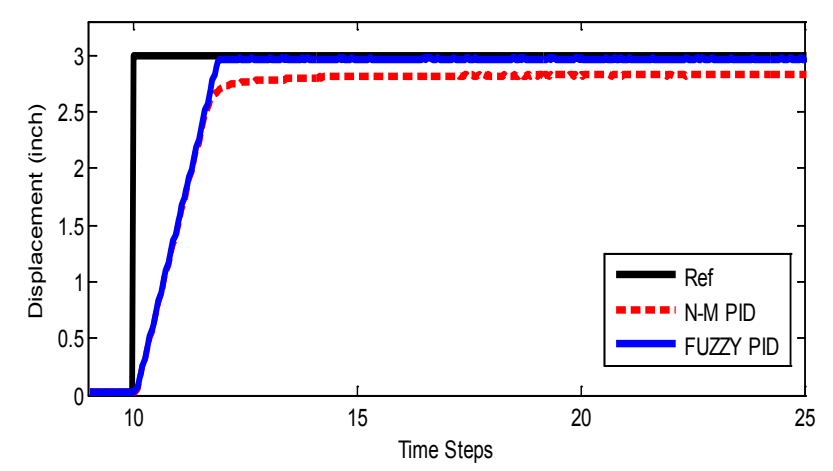

(a) Position tracking

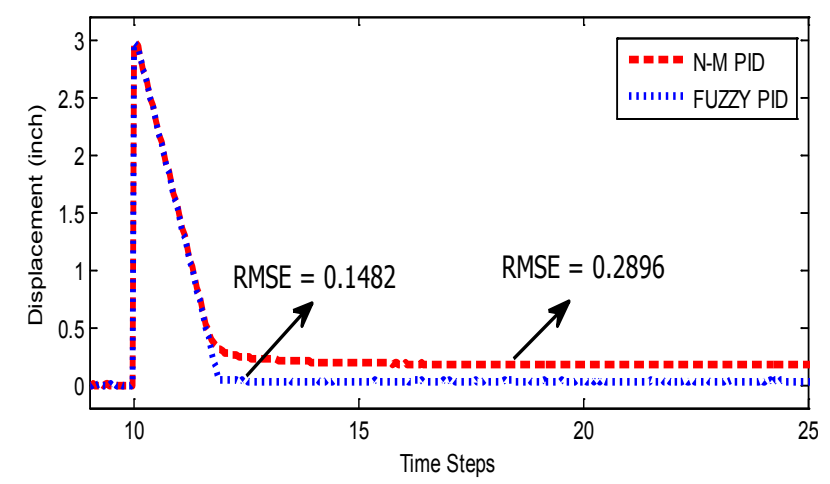

(b) Position tracking error

Figure 13. Experimental result of the step responses of N-M and Fuzzy PID (ARX221)

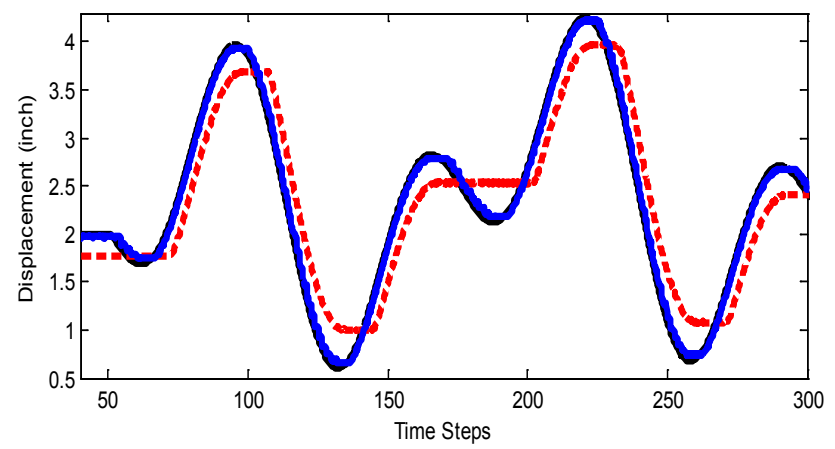

(a) Position tracking

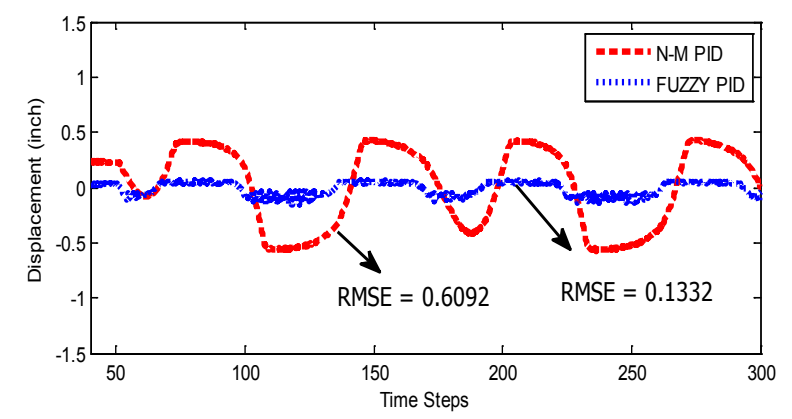

(b) Position tracking error

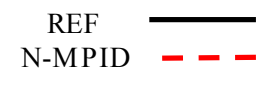

FUZZY PID

Figure 14. Experimental result of the sinusoidal responses of N-M and Fuzzy PID (ARX221)
Figure 9 and 10 shows the output response of both the N-M and Fuzzy PID controllers. It can be seen that both controllers satisfactorily reaches the steady-state without overshoot. A faster rise-time and settling-time are recorded in the Fuzzy PID response obtained from ARX221 model with PID setting $\mathrm{Kp}=5, \mathrm{Ki}=0.5$ and $\mathrm{Kd}=0$. Figure 11 and 12 shows resulting tracking when using sinusoidal responses. Figure 11 shows much better response that the one given in figure 12. In fact, the overlapping of reference and output signals cannot be seen.

Therefore, the simulation work was verified by applying the controller parameters $\left(\mathrm{K}_{\mathrm{p}}, \mathrm{K}_{\mathrm{i}}\right.$ and $\left.\mathrm{K}_{\mathrm{d}}\right)$ of ARX221 model to real system to achieve the best performance of the system. Hence, the results showed that the output of the system with the design controller by simulation and experiment were improved and almost similar.

Figure 13 shows the experimental output response of N-M and Fuzzy PID controllers. It can be seen that the Fuzzy PID satisfactorily reaches the steady-state without overshoot and reduced the error compare with N-M PID.

From Figure 14, the experimental result shows that N-M PID control responses has serious delay and large tracking error, while the response speed and tracking accuracy of self-tuning fuzzy PID control is better.

\section{Conclusions}

This study had implemented Nelder-Mead optimization to tune the PID parameters for a given constraints of desired step response. A self-tuning fuzzy PID controller was success fully developed and applied to the electro-hydraulic actuator using the parameters that have been optimized earlier by Nelder-Mead algorithm. The robustness and effectiveness of the designed controllers were verified through computer simulations and experiments. The results show that self-tuning fuzzy PID controller seems feasible to control the electro-hydraulic accord ing to desired reference signal. The proposed controller offers promising capabilities to guarantee the robustness and position tracking accuracy of the system. The position tracking performance was imp roved by using controller parameters value of $\mathrm{K}_{\mathrm{p}}, \mathrm{K}_{\mathrm{i}}$ and $\mathrm{K}_{\mathrm{d}}$ for second-order model.

\section{ACKNOWLEDGEMENTS}

The authors would like to thanks and acknowledge the FRGS-RMI-UiTM (600-RMI/ST/FRGS/5/3/Fst(85/2010) for financial support of this research work.

\section{REFERENCES}

[1] H.-M. Chen and J.-C.Renn, Juhng-Perng, "Sliding mode control with vary ing boundary layers for an electro-hy draulic 
position servo system", International Journal of Advanced Manufacturing Technology, vol. 26, pp. 117-123, 2005.

[2] R. Ghazali, Y. M. Sam, M. F. Rahmat, A. W. I. M. Hashim and ZulfatmanM. "Sliding Mode Control with PID Sliding Surface of an Electro-hydraulic Servo System", Australian Journal of Basic and Applied Sciences, 4(10), 2 pp. 4749-4759, 2010.

[3] M.F. Rahmat, with Zulfatman, "Application of self-tuning Fuzzy PID Controller on Industrial Hydraulic Actuator", International Journal on Smart Sensing and Intelligengent Systems, vol. 2, pp. 246-261, 2009.

[4] V. Bobal, J. Bohm, J. Fessl, and J. Machacek, Digital Self-tuning Controllers: Algorithms, Implementation and Applications, Springer, 2005.

[5] R. Adnan, M. Tajjudin, N. Ishak, H. Ismail, M. Hezri, and F. Rahiman, "Self-tuning Fuzzy PID Controller for ElectroHydraulic Cylinder", IEEE 7th International Colloquium on Signal Processing and its Applications, pp. 395-398, 2011.

[6] J. Wang, Y. Jing, and Z. Tong, "Application of Intelligent Integral Fuzzy Controller in Hydraulic Position Control", Chinese Journal of Scientific Instrument, vol.26, supplies no 12, pp. 798-799, 2005.

[7] R. Adnan, M.H. Fazalul Rahiman and A.M. Samad, "Model Identification and Controller Design for Real-Time Control of Hydraulic Cylinder", IEEE $6^{\text {th }}$ International Colloquium on Signal Processing and its Applications (CSPA), pp. 1-4, 2010.

[8] L. Ljung, System identification: Theory for the User, Prentice Hall, 1987.

[9] J.A. Nelder, and R. Mead, "A Simplex Method for Function Minimization”, Computer Journal, vol. 7, pp.308-313, 1965.

[10] Y. Lei, L. Xiangyang, W. Ningfei, and W. Feng, "The structure analysis and design of a new self-optimizing fuzzy controller based on Nelder-Mead simplex method", in Power Engineering and Automation Conference (PEAM), IEEE, pp. $136-139,2011$.

[11] M. Dub, Jalovecky, x, and R., "DC motor experimental parameter identification using the Nelder-Mead simplex method", in Power Electronics and Motion Control Conference (EPE/PEMC), 14th International, pp. S4-9-S4-11, 2010 .

[12] M. Tajjudin, N. Ishak, H. Ismail, M. H. F. Rahiman, and R. Adnan, "Optimized PID control using Nelder-Mead method for electro-hydraulic actuator systems", in Control and System Graduate Research Colloquium (ICSGRC), IEEE, pp. 90-93, 2011.

[13] A. Moraglio and C.G. Johnson, "Geometric Generalization of the Nelder-Mead Algorithm", EvoCOP, P. Cowling and P. Merz, eds., Springer-Verlag, pp. 190-201, 2010.

[14] L. Wang, Y. Xu, and L. Li, "Parameter identification of chaotic systems by hybrid Nelder - Mead simplex search and differential evolution algorithm", Expert Systems with Applications, vol. 38, pp. 3238-3245, 2011.

[15] B.K. Panigrahi and V.R. Pandi, "Bacterial foraging optimisation :Nelder - Mead hybrid algorithm for economic load dispatch", IET Generation, Transmission \& Distribution, vol. 2, pp. 556-565, 2008.

[16] Avila M. A., Loukianov A.G., and Sanchez E.N. "Electro-Hydraulic Trajectory Tracking", In Proceedings of the American Control Conference, Boston, Massachusetts., pp. 2603-2608, 2004.

[17] Kyoung K. A., Bao K.N., Yoon H.S. "Self Tuning Fuzzy PID Control for Hydraulic Load Simulator", Int. Conference on Control, Automation, and Systems, Ceox, Seoul, Korea. pp. 345-349, 2007. 